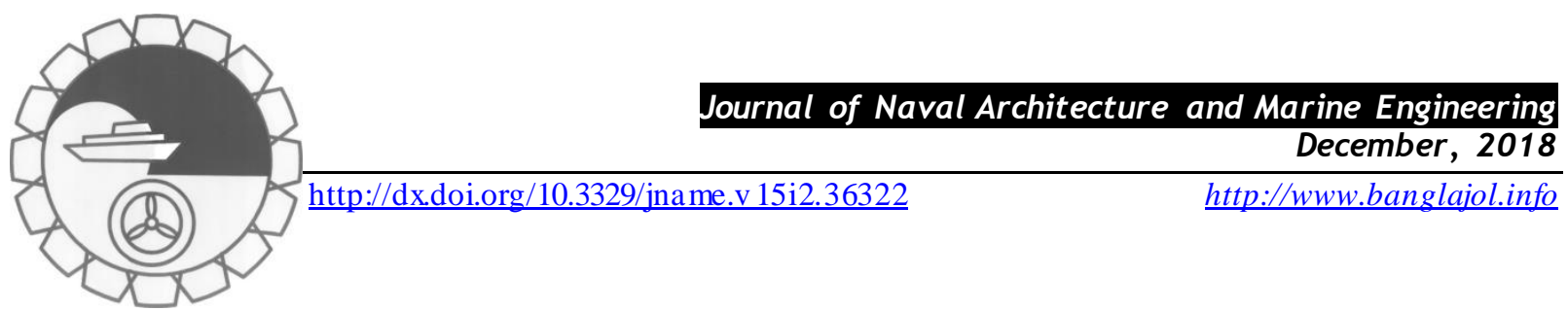

\title{
STATE SPACE MODELLING APPROACH FOR RUDDER ROLL STABILIZATION
}

\section{B. M. Shameem ${ }^{1}$ and Vinod Vincent ${ }^{2}$}

${ }^{1}$ Department of Naval Architecture and Offshore Engineering, Academy of Maritime Education and Training (AMET University), Chennai - 603 112, Email: shameemiit@ gmail.com

${ }^{2}$ Department of Naval Architecture and Offshore Engineering, Academy of Maritime Education and Training (AMET University), Chennai - 603 112, Email: vinodvincentamet @ gmail.com

\begin{abstract}
:
The control objective of the Rudder Roll Stabilization (RRS) system is to deploy the rudder, which is primarily a path controlling device, to reduce the roll motion without interference in heading of ship. To achieve the control of both roll and yaw motions, the only control input is the rudder angle and hence the RRS system is referred as a Single Input, Two Output (SITO) system. Rudder roll stabilization is insignificant at low forward speed of the ship, but can give significant control at higher speed when fast rudder movement is applied. This paper presents a closed loop state space model for accurate simulations on rudder roll stabilization in irregular seas considering the 3-degree of freedom motions, i.e., sway, roll and yaw. The computational model is developed to analyze the effect of the rudder movement on sway, roll and yaw in forward speed conditions in irregular sea conditions. The Sea State conditions are modelled as wave perturbation models using the method of shaping filter established by filtered white noise. The control system has been designed using optimal linear quadratic regulator (LQR) method. The control loop contains both the signal for the autopilot action to trigger the heading angle correction as well as the signal for rudder based roll motion control. The simulations are carried out with rudder roll control system ON and OFF mode to analyze the effect of the rudder on steering and motion stabilization. In both cases the autopilot is in active mode to correct deviations in the course heading. The simulations are analyzed for three different ship speeds in two different Seas State conditions with a low and fast rudder movement to show the efficacy of the model. The performance is evaluated and presented based on the RMS value. Since the rudder based roll motion stabilization may also result in unnecessary motions of sway and yaw, besides the desirable roll reduction, the result presents the sway-roll-yaw responses as applicable under the particular speed and Sea State conditions.
\end{abstract}

Keywords: Rudder roll stabilization, 3-degree of freedom motions, state-space model, irregular seas, shaping filter

\begin{tabular}{|c|c|c|c|}
\hline \multicolumn{4}{|c|}{ NOMENCLATURE } \\
\hline $\mathrm{y}$ & sway position, roll angle and yaw angle & $x$ & state variables \\
\hline $\mathrm{v}, \mathrm{p}$ and $\mathrm{r}$ & sway velocity, roll rate and yaw rate & $\mathrm{F}$ & system matrix \\
\hline $\mathrm{I}_{44+} \mathrm{A}_{44}$ & virtual mass moment of inertia & G & input matrix \\
\hline $\mathrm{B}_{44}$ & roll damping coefficient & $u$ & input control vector \\
\hline $\mathrm{C}_{44}$ & restoring moment coefficient & $\mathrm{Q}, \mathrm{R}$ & weighing matrices \\
\hline $\mathrm{E}_{\mathrm{wave}}$ & wave induced roll moment & \multicolumn{2}{|c|}{ Greek symbols } \\
\hline $\mathrm{E}_{\text {rudder }}$ & rudder-induced roll moment & $\phi$ & roll angle \\
\hline [A] & mass matrix including added mass & $\psi$ & yaw angle \\
\hline [B] & damping matrix & $\eta_{j}$ & response in the $\mathrm{j}^{\text {th }}$ direction \\
\hline $\mathrm{E}_{j}$ & excitation force or moment in the $\mathrm{j}^{\text {th }}$ direction & $\omega$ & wave frequency \\
\hline $\mathrm{S}(\omega)$ & wave amplitude spectral ordinate & $\omega_{e}$ & encountering frequency \\
\hline $\mathrm{S}(\mathrm{t})$ & wave slope & $\xi(\mathrm{t})$ & $x$-coordinate of wave level at origin \\
\hline $\mathrm{T}_{1}$ & characteristic period & $\Pi$ & disturbance dis tribution matrix \\
\hline $\mathrm{H}_{\mathrm{S}}$ & significant wave height & $\delta$ & actual rudder angle \\
\hline$Y_{D}, N_{D}, K_{D}$ & sway force, roll moment and yaw moment & $\delta_{\mathrm{c}}$ & commanded rudder angle \\
\hline
\end{tabular}




\section{Introduction}

An unusual means of roll reduction is by the use of the rudder though it is primarily a steering device. In this sense it is an attractive method and the rudder is by no means an additional appendage built unlike the fins, to reduce the roll motion. The method known as Rudder Roll Stabilization (RRS), is a single-input, two-output system (roll and yaw) coupled with rudder-induced sway. To be effective as a roll motion control device, the rudder must possess certain distinct characteristics namely, a relatively higher rudder rate. For RRS to be effective, a typical rudder turning rate of 5-20 deg/s is desirable (Fossen, 2011) with a consequent need for larger power in the steering gear system. These inherent characteristics make RRS more realizable for naval vessels. The rudder produces a yaw moment and also produces a roll moment due to its position at aft region and below the CG of the ship. Due to the smaller moment of inertia and damping in roll mode, the roll response of the rudder command is faster than the response in yaw mode. During this initial phase in which the rudder produces a roll moment, the effect of rudder on yaw angle is not appreciable due to larger yaw moment of inertia. Hence if proper phasing can be accomplished between roll and yaw characteristics, the rudder can be used as a roll stabilizer besides its primary function in course keeping. The factors influencing the performan ce of the rudder roll stabilization system include ship dynamics and ship speed, sea state conditions and wave encounter period and the type of control system.

The first successful practical implementation of rudder roll stabilization was taken up in the eighties by Baitis et al. (1983). The method of limiting the actuator activity was introduced by Amerongen et al. (1990) and later this work led to the integration of the rudder roll stabilization system into a single control system along with the autopilot functions. This development ensured the rudder fulfils the primary function of course keeping with additional roll stabilization and assisted for the further progress in RRS development. Zhou et al. (1990) presented a multi-variable adaptive controller using Recursive Prediction Error (RPE) method combined with Linear Quadratic Gaussian (LQG) controller for rudder roll stabilization. The RPE method directly identifies the ship and control dynamics and good control responses were obtained with regard to both heading and roll motion. Roberts (1993) studied the applicability of installation of the RRS sytem at an earlier stage of ship design. The studies relating to different rudder slew rate to obtain the maximum rudder angle demand, showed the influence of the rudder rate in using the rudder as a roll stabilization device. A typical rudder turning rate of 5-20 deg/s is desirable for effective RRS mechanis m with consequent need for larger power in the steering gear system. These inherent characteristics make RRS more realizable for naval vessels.

Oda et al. (1996) developed a Multivariate Auto-regressive Rudder roll Control System (MARCS) to improve the movement of the rudder excursion as smooth as possible. Blanke et al. (2000) presented the continuation of work on the SF300 vessels, which used different controllers manually switched according to the wave period observed by the operator. Other methods proposed includes, quantitative feedback theory by Hearns and Blanke (1998), a model predicative method by Perez et al. (2000), a nonlinear generalized minimum variance controller by Majecki et al. (2006) and a non-linear dynamic compensation method for rudder roll stabilization by O'Brien (2009). However for the RRS system, linear models were used since the primary functions of the rudders are in course keeping, and thus, making only small deviations from the steady state course Perez (2005) and (Perez and Blanke, 2012). Kapitanyuk et al. (2016) discussed the rudder roll stabilization based on Optimal Universal Control (OUC). This approach attempts to solve the problem of linear quadratic optimization in presence of uncertain external disturbances. Literature review suggests that the RRS is quite comparable to the performance of the Fin Roll Stabilization (FRS) system to achieve good roll reduction, provided there is increased rudder angle rate of movement.

The emphasis of this paper is on the development of a computational state space model for rudder roll stabilization incorporating 3-degrees of freedom, i.e., sway-roll-yaw motions in irregular seas. The state space representation of the system provides an appropriate and compact way of examining the system behaviour in various operating conditions. The model is developed using a MATLAB based code in Simulink. The wave excitation causing sway force, roll moment and yaw moment, were modelled using the method of shaping filter through white noise filtering. The state space model discussed here helps to analyze the 3-DOF performance of RRS and for examining multiple scenarios such as response in different Sea-States for different rate of turn of rudder. 


\section{System dynamics}

\subsection{Mathematical formulation}

The mathematical model representing the rudder roll stabilization is modelled, considering rudder as a pair of fin stabilizer placed at the aft, below the C.G of the ship. Rudder as a roll damping device requires a frequency separation between roll and yaw. The roll moment of inertia is relatively smaller than yaw moment of inertia; hence the roll response of the rudder command is faster than the response in yaw mode. The high frequency movement of rudder is used for roll motion control while low frequency movements are used for the purpose of course keeping. A 3-DOF model with sway, roll and yaw modes are considered. The candidate vessel is a highspeed frigate vessel and the principal characteristics of ship and rudder are given in Table 1. A right-handed coordinate system with origin fixed on ship's center of gravity is considered for expressing the equations of motion. The variables $\mathrm{y}, \mathrm{v}, \phi, \mathrm{p}, \psi$ and $\mathrm{r}$ are used to represent sway position, sway velocity, roll angle, roll rate, yaw angle and yaw rate respectively.

Table 1: Main particulars of the vessel and rudder

Ship particulars

Ship particulars

Length, $\mathrm{L}_{\mathrm{BP}}$

Displacement

Max. beam

Draft

Metacentric height $\left(\mathrm{GM}_{\mathrm{T}}\right)$

Design Speed

Sprint speed

$\begin{array}{ll}86.30 \mathrm{~m} & \text { Natural roll period } \\ 1368 \text { tons } & \text { LCG from transom } \\ 10.10 \mathrm{~m} & \text { VCG from keel } \\ 3.15 \mathrm{~m} & \mathrm{~K}_{\mathrm{xx}} \\ 1.0 \mathrm{~m} & \mathrm{~K}_{\mathrm{yy}} \\ 15.0 \text { knots } & \mathrm{K}_{\mathrm{zz}}\end{array}$

$28.0 \mathrm{knots}$
$9.44 \mathrm{~s}$

$40.10 \mathrm{~m}$

$3.87 \mathrm{~m}$

$4.50 \mathrm{~m}$

$25.56 \mathrm{~m}$

$25.56 \mathrm{~m}$

\section{Rudder data}

$\begin{array}{ll}\text { Number of rudders } & 2 \\ \text { Profile area (each) } & 5.51 \mathrm{~m}^{2} \\ \text { Geometric aspect ratio } & 1.53 \\ \text { Mean chord } & 1.9 \mathrm{~m} \\ \text { Mean span } & 2.9 \mathrm{~m} \\ \text { Lift coefficient slope } & 0.047 / \mathrm{deg}\end{array}$

The single degree of freedom roll motion equation with rudder as anti-roll device is expressed as:

$$
\left(\mathrm{I}_{44}+\mathrm{A}_{44}\right) \ddot{\phi}+\mathrm{B}_{44} \dot{\phi}+\mathrm{C}_{44} \phi=\mathrm{E}_{\mathrm{wave}}+\mathrm{E}_{\text {rudder }}
$$

By linear theory, for a given frequency the amplitude of harmonic response is directly proportional to the exciting force or moment, with a phase shift. Let $\eta_{j}$ be the response in the $\mathrm{j}^{\text {th }}$ direction and thus the ship motion will have the form (Lewis, 1989),

$\eta_{j}(t)=\left|\eta_{j}\right| \cos \left(\omega_{e} t+\sigma_{j}\right)=\eta_{j} e^{i \omega_{e} t}$

where, $j=1,2, \ldots 6$

also, $\mathrm{E}(t)=\left|\mathrm{E}_{j}\right| \cos \left(\omega_{e} t+\sigma_{j}\right)=\left|\mathrm{E}_{j}\right| e^{i \omega_{e} t}$

Now, the simplified 3-DOF equation of motion can be written in complex form,

$\left[\left(-\omega_{e}^{2}\right)[\mathrm{A}]+i \omega_{e}[\mathrm{~B}]+[\mathrm{C}]\right]\left\{\eta_{j}\right\} e^{i \omega_{e} t}=\left\{\mathrm{E}_{j}\right\} e^{i \omega_{e} t}$

For the controller design, it is assumed that the coefficient matrices are independent of frequency and the ship is moving at design speed, equation (4) is modified as (Sgobbo and Parsons, 1999):

$$
\ddot{\eta}=-[\mathrm{A}]^{-1}[\mathrm{~B}]\{\dot{\eta}\}-[\mathrm{A}]^{-1}[\mathrm{C}]\{\eta\}+[\mathrm{A}]^{-1}\left\{\mathrm{E}_{j}\right\}
$$

The motion coefficients are obtained using the strip theory program, SEAWAY for three different speeds for a wave heading angle of 90 degree, which yields largest RMS roll amplitude for the candidate vessel. The strip theory program is capable of giving equivalent linear viscous roll damping coefficient through an iterative process (Journee, 2001). The coefficients established for the bare hull is written in general matrix form:

$$
[A]=\left[\begin{array}{lll}
a_{22} & a_{24} & a_{26} \\
a_{42} & a_{44} & a_{46} \\
a_{62} & a_{64} & a_{66}
\end{array}\right] \quad[B]=\left[\begin{array}{lll}
b_{22} & b_{24} & b_{26} \\
b_{42} & b_{44} & b_{46} \\
b_{62} & b_{64} & b_{66}
\end{array}\right]
$$




$$
[\mathrm{C}]=\left[\begin{array}{lll}
\mathrm{c}_{22} & \mathrm{c}_{24} & \mathrm{c}_{26} \\
\mathrm{c}_{42} & \mathrm{c}_{44} & \mathrm{c}_{46} \\
\mathrm{c}_{62} & \mathrm{c}_{64} & \mathrm{c}_{66}
\end{array}\right] \text { and }\{\eta\}=\left[\begin{array}{l}
\eta_{2} \\
\eta_{4} \\
\eta_{6}
\end{array}\right]=\left[\begin{array}{c}
y \\
\phi \\
\psi
\end{array}\right]
$$

where 2, 4 and 6 represents sway, roll and yaw respectively. The effects of the rudders are incorporated into the bare hull coefficient matrices as given by Sgobbo and Parsons (1999). The flow velocities towards the rudders are also considered with respect to ship speed based on momentum theory. With the inclusion of rudder based terms, the mass and damping matrices will have the following form,

$$
\begin{aligned}
& {[\mathrm{A}]_{\text {rudder }}=\left[\begin{array}{lll}
\mathrm{a}_{22}+\mathrm{a}_{22 \mathrm{r}} & \mathrm{a}_{24}+\mathrm{a}_{24 \mathrm{r}} & \mathrm{a}_{26}+\mathrm{a}_{26 \mathrm{r}} \\
\mathrm{a}_{42}+\mathrm{a}_{42 \mathrm{r}} & \mathrm{a}_{44}+\mathrm{a}_{44 \mathrm{r}} & \mathrm{a}_{46}+\mathrm{a}_{46 \mathrm{r}} \\
\mathrm{a}_{62}+\mathrm{a}_{62 \mathrm{r}} & \mathrm{a}_{64}+\mathrm{a}_{64 \mathrm{r}} & \mathrm{a}_{66}+\mathrm{a}_{66 \mathrm{r}}
\end{array}\right]} \\
& {[\mathrm{B}]_{\text {rudder }}=\left[\begin{array}{lll}
\mathrm{b}_{22}+\mathrm{b}_{22 \mathrm{r}} & \mathrm{b}_{24}+\mathrm{b}_{24 \mathrm{r}} & \mathrm{b}_{26}+\mathrm{b}_{26 \mathrm{r}} \\
\mathrm{b}_{42}+\mathrm{b}_{42 \mathrm{r}} & \mathrm{b}_{44}+\mathrm{b}_{44 \mathrm{r}} & \mathrm{b}_{46}+\mathrm{b}_{46 \mathrm{r}} \\
\mathrm{b}_{62}+\mathrm{b}_{62 \mathrm{r}} & \mathrm{b}_{64}+\mathrm{b}_{64 \mathrm{r}} & \mathrm{b}_{66}+\mathrm{b}_{66 \mathrm{r}}
\end{array}\right]} \\
& \{\mathrm{E}\}_{\text {rudder }}=\left[\begin{array}{l}
\mathrm{Y}_{\delta} \\
\mathrm{K}_{\delta} \\
\mathrm{N}_{\delta}
\end{array}\right][\delta] \text { and }\{\mathrm{E}\}_{\text {wave }}=\left[\begin{array}{c}
\mathrm{Y}_{\mathrm{D}} \\
\mathrm{K}_{\mathrm{D}} \\
\mathrm{N}_{\mathrm{D}}
\end{array}\right]
\end{aligned}
$$

where $\mathrm{Y}$ is sway force, $\mathrm{K}$ is roll moment and $\mathrm{N}$ is yaw moment with respect to rudder deflection and wave excitation. The suffix ' $r$ ' represents the rudder parameters and $\delta$ is the actual rudder deflection.

\subsection{Wave perturbation model}

The wave perturbation model uses the method of shaping filter, which is based on random process theory to establish the irregular sea condition through white noise filtering. The performance of rudder as a roll stabilizer is analyzed for two selected Sea States, 4 and 5. The excitation is caused by forces and moments induced by the actual wave disturbances acting on the ship. These forces and moments are equivalent wave loads that acts at the CG of the ship and obtained from the wave input distributed along the ship's length. They are de fined as sway force $\left(Y_{D}\right)$, roll moment $\left(N_{D}\right)$ and yaw moment $\left(K_{D}\right)$. The forces and moments are dependent on the ship speed and the relative heading with respect to the wave direction. These functions are computed numerically using the strip integration method and the knowledge of ship's geometry. The sea state spectrum used for the present study takes the form of ITTC 2-parameter wave spectrum that permits wave period and wave height to be assigned separately, defined by the following:

$\mathrm{S}(\omega)=\frac{173 \mathrm{H}_{\mathrm{S}}^{2}}{\mathrm{~T}_{1}^{4} \omega^{5}} \exp \left(\frac{-691}{\mathrm{~T}_{1}^{4} \omega^{4}}\right)$

where $S(\omega)$ is the wave amplitude spectral ordinate, $H_{S}$ is the significant wave height in $m, \omega$ is the wave frequency in rad/s and $T_{1}$ is the period corresponding to average frequency of component waves. The definition tables for the selected Sea States are given in Table 2.

Table 2: Sea State definition table

\begin{tabular}{|c|c|c|}
\hline Sea state & $\begin{array}{c}\text { Significant wave height, } \\
\mathrm{H}_{\mathrm{s}}(\mathrm{m})\end{array}$ & $\begin{array}{c}\text { Characteristic period, } \\
\mathrm{T}_{1}(\mathrm{~s})\end{array}$ \\
\hline 4 & 1.9 & 8.8 \\
\hline 5 & 3.3 & 9.7 \\
\hline
\end{tabular}


The equivalent excitation forces and moments are approximated (Kallstrom, 1981) as:

$$
\begin{aligned}
& \mathrm{Y}_{\mathrm{D}}=\mathrm{m} \cdot a_{1} \cdot \mathrm{S}(\mathrm{t}) \\
& \mathrm{K}_{\mathrm{D}}=\mathrm{m} \cdot \mathrm{L}_{\mathrm{BP}} \cdot a_{3} \cdot \mathrm{S}(\mathrm{t}) \\
& \mathrm{N}_{\mathrm{D}}=\mathrm{m} \cdot \mathrm{L}_{\mathrm{BP}} \cdot a_{2} \cdot \xi(\mathrm{t})
\end{aligned}
$$

where $m$ is the mass of the ship, $L_{B P}$ is the length between perpendiculars, $\xi(t)$ is the xco-ordinate of the wave level at origin, $\mathrm{S}(\mathrm{t})$ is the wave slope and $\overline{a_{1}}, \overline{a_{2}}$ and $\overline{a_{3}}$ are real numbers used to regulate the excitation spectra. The wave slope and wave height are obtained using the method of shaping filter as explained in Shameem and Subramanian (2014). The steps are briefly reproduced here for completeness. The standard wave spectrum is approximated for the desired Sea State using a rational polynomial. The expression for the selected polynomial is,

$$
\mathrm{S}_{\mathrm{R}}(\omega)=\frac{\mathrm{b}_{2}^{2} \omega^{2}}{\omega^{6}+\left(\mathrm{a}_{1}^{2}-2 \mathrm{a}_{2}\right) \omega^{4}+\left(\mathrm{a}_{2}^{2}-2 \mathrm{a}_{1} \mathrm{a}_{3}\right) \omega^{2}+\mathrm{a}_{3}^{2}}
$$

where $a_{1}, a_{2}, a_{3}$ and $b_{2}$ are real numbers. The coefficients of the rational polynomial are obtained by establishing $\mathrm{N}$ algebraic equations by least square fitting of the polynomial. The established rational spectrum is then decomposed to get the desired transfer function of the shaping filter. The filters repres enting the amplitude and slope are transferred into a state space form to obtain single-input and two-output system. By inputting a stationary Guassian white noise signal to the state space representation, the desired sea can be realized in the form of wave elevation and wave slope. A spectral analysis using Welch method (Welch, 1967) has been carried out to check the wave spectrum against the filter output. A close correlation is achieved and the spectral analys is confirms the Sea State spectra. The comparison of wave spectrum with the rational spectrum and shaping filter for selected sea states are shown in Fig.1.

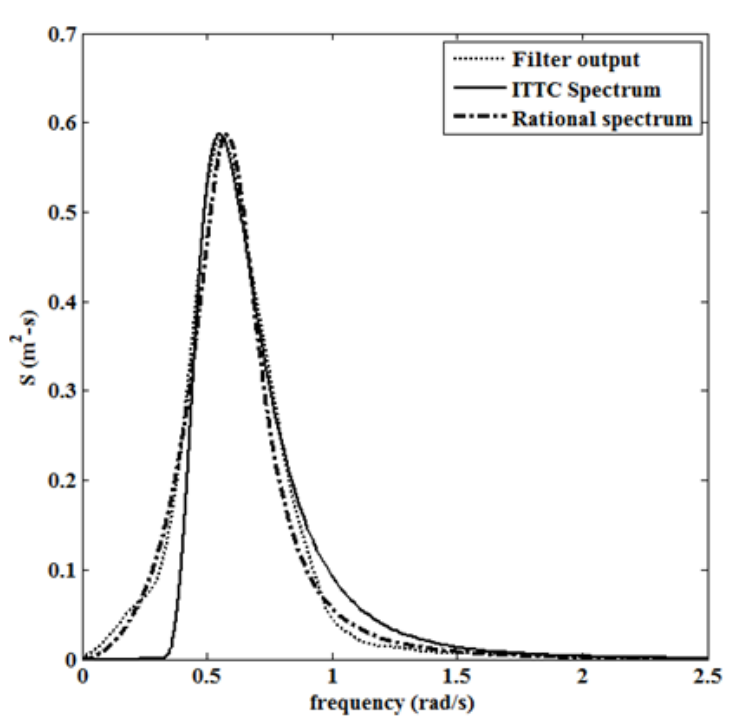

(a) Sea State 4

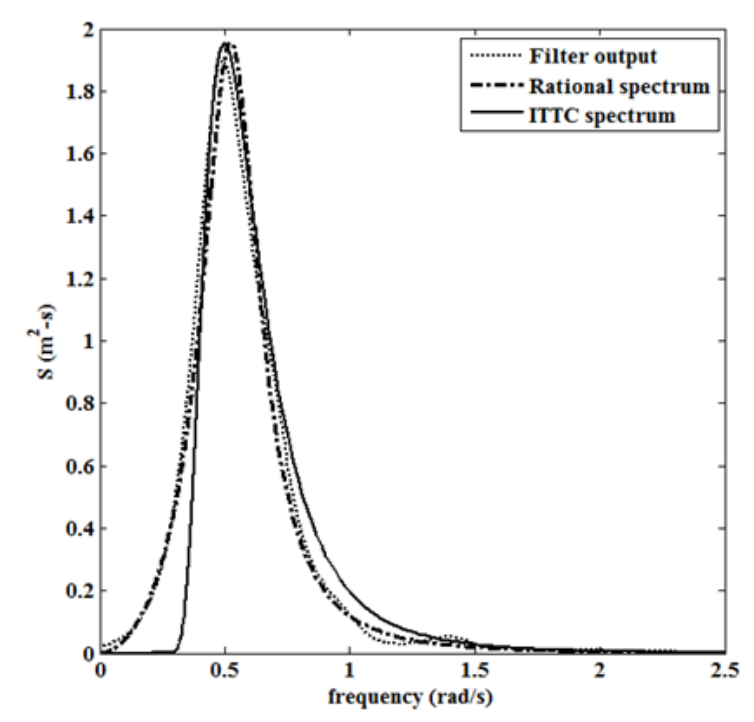

(b) Sea State 5

Fig. 1: Comparison of wave spectrum with rational spectrum and shaping filter for Sea State 4 and 5

From the strip theory program, the Froude-Krylov and diffraction exciting forces and moments are calculated for the desired sea conditions. The excitation forces are obtained for three different ship speeds, 10, 15 and 20 knots in a 90 degree wave heading angle. A spectral density function or power spectrum is obtained for the excitation forces and moments through strip theory integration, which can be expressed as: 


$$
\begin{aligned}
& \mathrm{G}_{\text {sway }}(\omega)=\mathrm{S}_{\xi \xi}\left|\mathrm{F}_{22}(\omega)\right|^{2} \\
& \mathrm{G}_{\text {roll }}(\omega)=\mathrm{S}_{\xi \xi}\left|\mathrm{F}_{44}(\omega)\right|^{2} \\
& \mathrm{G}_{\text {yaw }}(\omega)=\mathrm{S}_{\xi \xi}\left|\mathrm{F}_{66}(\omega)\right|^{2}
\end{aligned}
$$

where $F_{22}, F_{44}$, and $F_{66}$ are the wave loads obtained for sway, roll and yaw from strip theory program and $S_{\xi \xi}$ is the spectrum with respect to encountering frequency. For a 90 deg ree wave heading, the encountering frequency is same as the wave frequency. The excitation forces and moments related to sway, roll and yaw spectra are expressed as,

$$
\begin{aligned}
\mathrm{Y}_{\mathrm{D}}^{2} & =\mathrm{G}_{\text {sway }}(\omega) \\
\mathrm{K}_{\mathrm{D}}^{2} & =\mathrm{G}_{\text {roll }}(\omega) \\
\mathrm{N}_{\mathrm{D}}^{2} & =\mathrm{G}_{\text {yaw }}(\omega)
\end{aligned}
$$

A filter output of excitation force and moments can be obtained by matching the spectra obtained from Eq. (15) to (17) with Eq. (11) to (13). This is done by substituting the rational polynomial in Eq. (11) to (13) and fixing $\bar{a}_{1}, \bar{a}_{2}$ and $\bar{a}_{3}$ to match the excitation spectra (Sgobbo and Parsons, 1999). For best matching the shaping filter, the parameters $a_{1}, a_{2}, a_{3}$ and $b_{2}$ can also be adjusted so that the best approximation of exciting force and moments are achieved. Thus, the wave perturbation for 3-DOF model is effectively simulated. In beam sea wave conditions, the effect of wave loads on sway and roll are same and hence the excitation forces and moments generated for 15 knots ship speed is used for modelling the system. The yaw moment has been approximated for all the cases. The generated time series for sway force, roll moment and yaw moment for a typical case of Sea State 5 is shown in Fig.2. The filter approximation for sway, roll and yaw for Sea State 4 and 5 at ship speed 15 knots are shown in Fig.3.
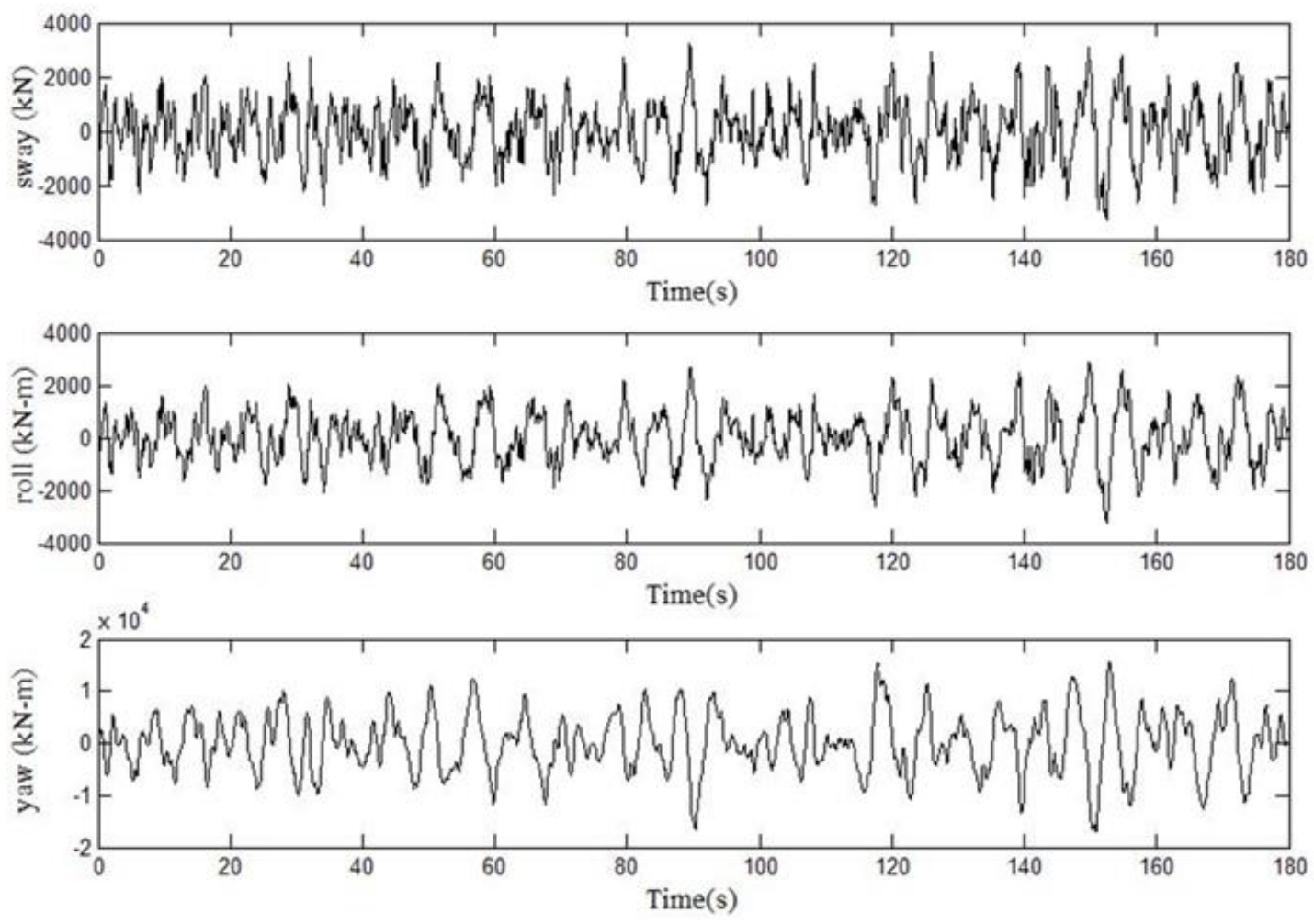

Fig.2: Excitation force and moment for Sea State 5, ship speed 15 knots 

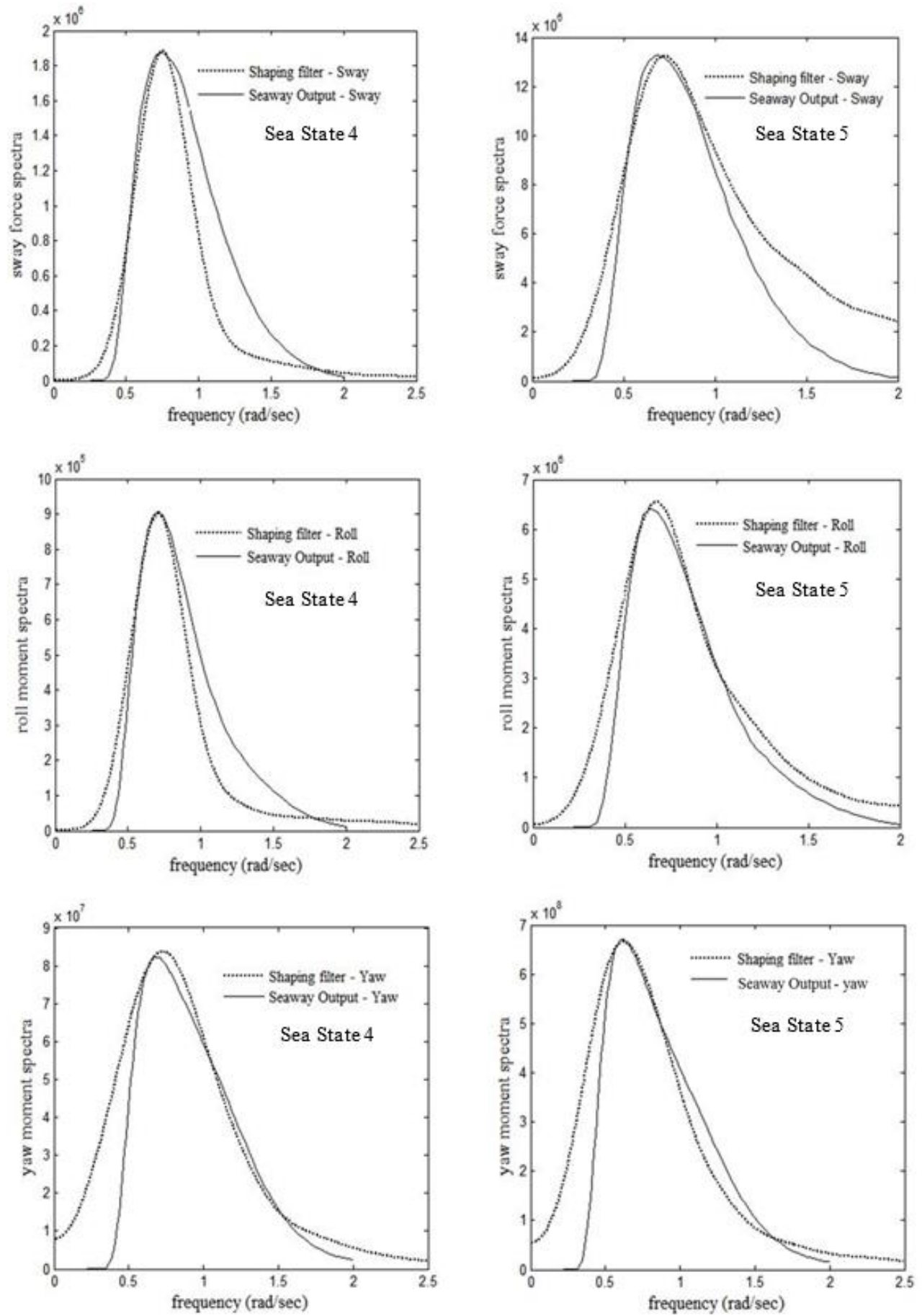

Fig.3: Filter approximation for force and moment spectra for Sea State 4 and 5

\section{State space formulation}

Eq. (5) is re-written after the inclusion of rudder effects in mass and damping terms as:

$$
\ddot{\eta}=\left[\mathrm{X}_{\mathrm{r}}\right]\{\dot{\eta}\}+\left[\mathrm{Y}_{\mathrm{r}}\right]\{\eta\}+\left[\mathrm{Z}_{\mathrm{r}}\right][\delta]
$$

where, $\left[\mathrm{X}_{\mathrm{r}}\right]=-[\mathrm{A}]_{\text {rudder }}^{-1}[\mathrm{~B}]_{\text {rudder }},\left[\mathrm{Y}_{\mathrm{r}}\right]=-[\mathrm{A}]_{\text {rudder }}^{-1}[\mathrm{C}]$, and $\left[\mathrm{Z}_{\mathrm{r}}\right]=[\mathrm{A}]_{\text {rudder }}^{-1}[\mathrm{E}]_{\text {rudder }}$ 
Let $x_{1}=\mathrm{y}, x_{2}=\mathrm{v}, x_{3}=\phi, x_{4}=\mathrm{p}, x_{5}=\psi$, and $x_{6}=\mathrm{r}$ be the state variables of the system. It is to be noted that $x_{1}$, $x_{2}$, and $x_{3}$ are not to be confused with the traditional representation for the other degrees of freedom in ship motion. Also let each term associated with $X_{r}$ is numbered as $X_{r(1,1)}, X_{r(1,2)}, \ldots$ and that of $Y_{r}$ as $\mathrm{Y}_{\mathrm{r}(1,1)}, \mathrm{Y}_{\mathrm{r}(1,2)}, \ldots$ and $\mathrm{Z}_{\mathrm{r}}$ is $\mathrm{Z}_{\mathrm{r}(1,1)}, \mathrm{Z}_{\mathrm{r}(2,2)}$ and $\mathrm{Z}_{\mathrm{r}(3,3)}$. By above considerations, Eq. (21) is expanded as,

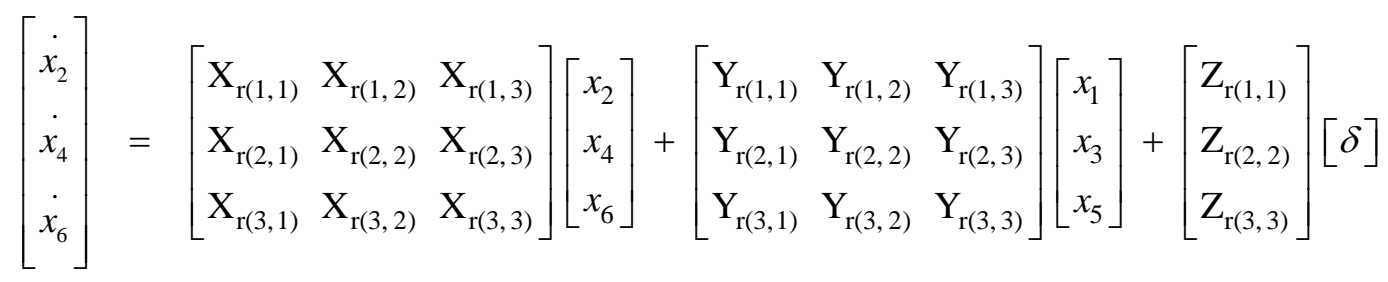

Eq. (22) is now expressed in the following state space form,

$$
\dot{x}=\mathrm{F} x+\mathrm{G} u
$$

$$
\left[\begin{array}{c}
\dot{x_{1}} \\
\dot{x_{2}} \\
\dot{x_{3}} \\
\dot{x_{4}} \\
\dot{x_{5}} \\
\dot{x_{6}}
\end{array}\right]=\left[\begin{array}{ccllll}
0 & 1 & 0 & 0 & 0 & 0 \\
\mathrm{Y}_{\mathrm{r}(1,1)} & \mathrm{X}_{\mathrm{r}(1,1)} & \mathrm{Y}_{\mathrm{r}(1,2)} & \mathrm{X}_{\mathrm{r}(1,2)} & \mathrm{Y}_{\mathrm{r}(1,3)} & \mathrm{X}_{\mathrm{r}(1,3)} \\
0 & 0 & 0 & 1 & 0 & 0 \\
\mathrm{Y}_{\mathrm{r}(2,1)} & \mathrm{X}_{\mathrm{r}(2,1)} & \mathrm{Y}_{\mathrm{r}(2,2)} & \mathrm{X}_{\mathrm{r}(2,2)} & \mathrm{Y}_{\mathrm{r}(2,3)} & \mathrm{X}_{\mathrm{r}(2,3)} \\
0 & 0 & 0 & 0 & 0 & 1 \\
\mathrm{Y}_{\mathrm{r}(3,1)} & \mathrm{X}_{\mathrm{r}(3,1)} & \mathrm{Y}_{\mathrm{r}(3,2)} & \mathrm{X}_{\mathrm{r}(3,2)} & \mathrm{Y}_{\mathrm{r}(3,3)} & \mathrm{X}_{\mathrm{r}(3,3)}
\end{array}\right]\left[\begin{array}{c}
x_{1} \\
x_{2} \\
x_{3} \\
x_{4} \\
x_{5} \\
x_{6}
\end{array}\right]+\left[\begin{array}{c}
0 \\
\mathrm{Z}_{\mathrm{r}(1,1)} \\
0 \\
\mathrm{Z}_{\mathrm{r}(2,2)} \\
0 \\
\mathrm{Z}_{\mathrm{r}(3,3)}
\end{array}\right][\delta]
$$

with the state vector, $x=\left[\begin{array}{llllll}x_{1} & x_{2} & x_{3} & x_{4} & x_{5} & x_{6}\end{array}\right]^{\mathrm{T}}$

During the initial analysis of the simulation, it has been noticed that the sway position in Eq.24 has no effect on the system. With this the state vector reduces to $x=\left[\begin{array}{lllll}x_{2} & x_{3} & x_{4} & x_{5} & x_{6}\end{array}\right]^{\mathrm{T}}$

With the inclusion of wave perturbation, the state space form for the equation of motion is represented as,

$$
\dot{x}=\mathrm{F} x+\mathrm{G} u+\Pi\{\mathrm{E}\}_{\text {wave }}
$$

where, $\Pi$ is the disturbance distribution matrix. This contains the parameters of $[\mathrm{A}]^{-1}$ from Eq.5.

$$
\Pi=\left[\begin{array}{ccc}
{[\mathrm{A}]_{11}^{-1}} & {[\mathrm{~A}]_{12}^{-1}} & {[\mathrm{~A}]_{13}^{-1}} \\
0 & 0 & 0 \\
{[\mathrm{~A}]_{21}^{-1}} & {[\mathrm{~A}]_{22}^{-1}} & {[\mathrm{~A}]_{23}^{-1}} \\
0 & 0 & 0 \\
{[\mathrm{~A}]_{31}^{-1}} & {[\mathrm{~A}]_{32}^{-1}} & {[\mathrm{~A}]_{33}^{-1}}
\end{array}\right]
$$

In the next step, the dynamics of steering gear are included in the closed loop state equations for the purpose of inclusion of autopilot mode for the Rudder Roll Control System (RRCS). The steering gear dynamics is expressed as,

$$
\dot{\delta}=\left(-\delta+\delta_{\mathrm{c}}\right) / \mathrm{T}_{\mathrm{c}}
$$

where $\delta$ and $\delta_{\mathrm{c}}$ are the actual and commanded rudder angle and $\mathrm{T}_{\mathrm{c}}$ is the time constant. For inclusion of autopilot with RRCS, the system dynamics is incorporated the steering gear dynamics and the wave perturbation model. 
Now, the state space equation for 3-DOF model is expanded into the following form:

$$
\begin{aligned}
& {\left[\begin{array}{c}
\dot{x}_{2} \\
\dot{x_{3}} \\
\dot{x_{4}} \\
\dot{x_{5}} \\
\dot{x}_{6} \\
\dot{\delta}_{a}
\end{array}\right]=\left[\begin{array}{cccccc}
\mathrm{X}_{\mathrm{r}(1,1)} & \mathrm{Y}_{\mathrm{r}(1,2)} & \mathrm{X}_{\mathrm{r}(1,2)} & \mathrm{Y}_{\mathrm{r}(1,3)} & \mathrm{X}_{\mathrm{r}(1,3)} & \mathrm{Z}_{\mathrm{r}(1,1)} \\
0 & 0 & 1 & 0 & 0 & 0 \\
\mathrm{X}_{\mathrm{r}(2,1)} & \mathrm{Y}_{\mathrm{r}(2,2)} & \mathrm{X}_{\mathrm{r}(2,2)} & \mathrm{Y}_{\mathrm{r}(2,3)} & \mathrm{X}_{\mathrm{r}(2,3)} & \mathrm{Z}_{\mathrm{r}(2,2)} \\
0 & 0 & 0 & 0 & 1 & 0 \\
\mathrm{X}_{\mathrm{r}(3,1)} & \mathrm{Y}_{\mathrm{r}(3,2)} & \mathrm{X}_{\mathrm{r}(3,2)} & \mathrm{Y}_{\mathrm{r}(3,3)} & \mathrm{X}_{\mathrm{r}(3,3)} & \mathrm{Z}_{\mathrm{r}(3,3)} \\
0 & 0 & 0 & 0 & 0 & -\frac{1}{\mathrm{~T}_{\mathrm{c}}}
\end{array}\right]\left[\begin{array}{c}
x_{2} \\
x_{3} \\
x_{4} \\
x_{5} \\
x_{6} \\
\delta
\end{array}\right]+\left[\begin{array}{c}
0 \\
0 \\
0 \\
0 \\
0 \\
\frac{\mathrm{T}_{\mathrm{c}}}{1}
\end{array}\right] \delta_{\mathrm{c}}} \\
& +\left[\begin{array}{ccc}
{[\mathrm{A}]_{(1,1)}^{-1}} & {[\mathrm{~A}]_{(1,2)}^{-1}} & {[\mathrm{~A}]_{(1,3)}^{-1}} \\
0 & 0 & 0 \\
{[\mathrm{~A}]_{(2,1)}^{-1}} & {[\mathrm{~A}]_{(2,2)}^{-1}} & {[\mathrm{~A}]_{(2,3)}^{-1}} \\
0 & 0 & 0 \\
{[\mathrm{~A}]_{(3,1)}^{-1}} & {[\mathrm{~A}]_{(3,2)}^{-1}} & {[\mathrm{~A}]_{(3,3)}^{-1}} \\
0 & 0 & 0
\end{array}\right]\left[\begin{array}{c}
\mathrm{Y}_{\mathrm{D}} \\
0 \\
\mathrm{~K}_{\mathrm{D}} \\
0 \\
\mathrm{~N}_{\mathrm{D}} \\
0
\end{array}\right]
\end{aligned}
$$

with the new state vector,

$$
x=\left[\begin{array}{llllll}
x_{2} & x_{3} & x_{4} & x_{5} & x_{6} & \delta
\end{array}\right]^{\mathrm{T}}
$$

Thus, the above state space description is used in modelling a computational model setup using Simulink. The state space model developed for rudder roll stabilization incorporating the autopilot is shown in Fig.4. The corresponding mathematical expressions are specified through user-defined function (Fcn block) in Simulink. The MUX block combines several inputs from the user defined functions into a single vector output. The inputs to MUX can be scalar or vector, and the output of MUX block is always a vector. In the state space model presented, $u(i)$ represents the $i^{\text {th }}$ element of the vector, for example $u(1)$ represents the first element. The green colored block is the integrator block. The autopilot function is incorporated in 'Fcn 6' block and the wave perturbation has given as an external disturbance to the model.

\section{Control System}

The system is successfully checked for controllability. The controller for the closed loop system is carried out using the optimal linear quadratic regulator (LQR) method. The optimal controller was designed for a design ship speed of 15 knots. To design an optimal LQR, the performance index is defined with respect to weighting matrices $\mathrm{Q}$ and $\mathrm{R}$.

$$
\mathrm{J}=\int_{0}^{\infty}\left(x^{\mathrm{T}} \cdot \mathrm{Q} x+u^{\mathrm{T}} \cdot \mathrm{R} \mathrm{u}\right) \mathrm{dt}
$$

where $u$ is the input control vector and $x$ is the state vector and the Eigen values of $\mathrm{Q}$ to be non-negative and $\mathrm{R}$ to be positive. The matrices $\mathrm{Q}$ and $\mathrm{R}$ are selected so that good roll reduction is obtained,

$$
\mathrm{Q}=\left[\begin{array}{cccccc}
0.1 & 0 & 0 & 0 & 0 & 0 \\
0 & 1 & 0 & 0 & 0 & 0 \\
0 & 0 & 1000 & 0 & 0 & 0 \\
0 & 0 & 0 & 1 & 0 & 0 \\
0 & 0 & 0 & 0 & 0.1 & 0 \\
0 & 0 & 0 & 0 & 0 & 1
\end{array}\right] \text { and } \mathrm{R}=[1]
$$




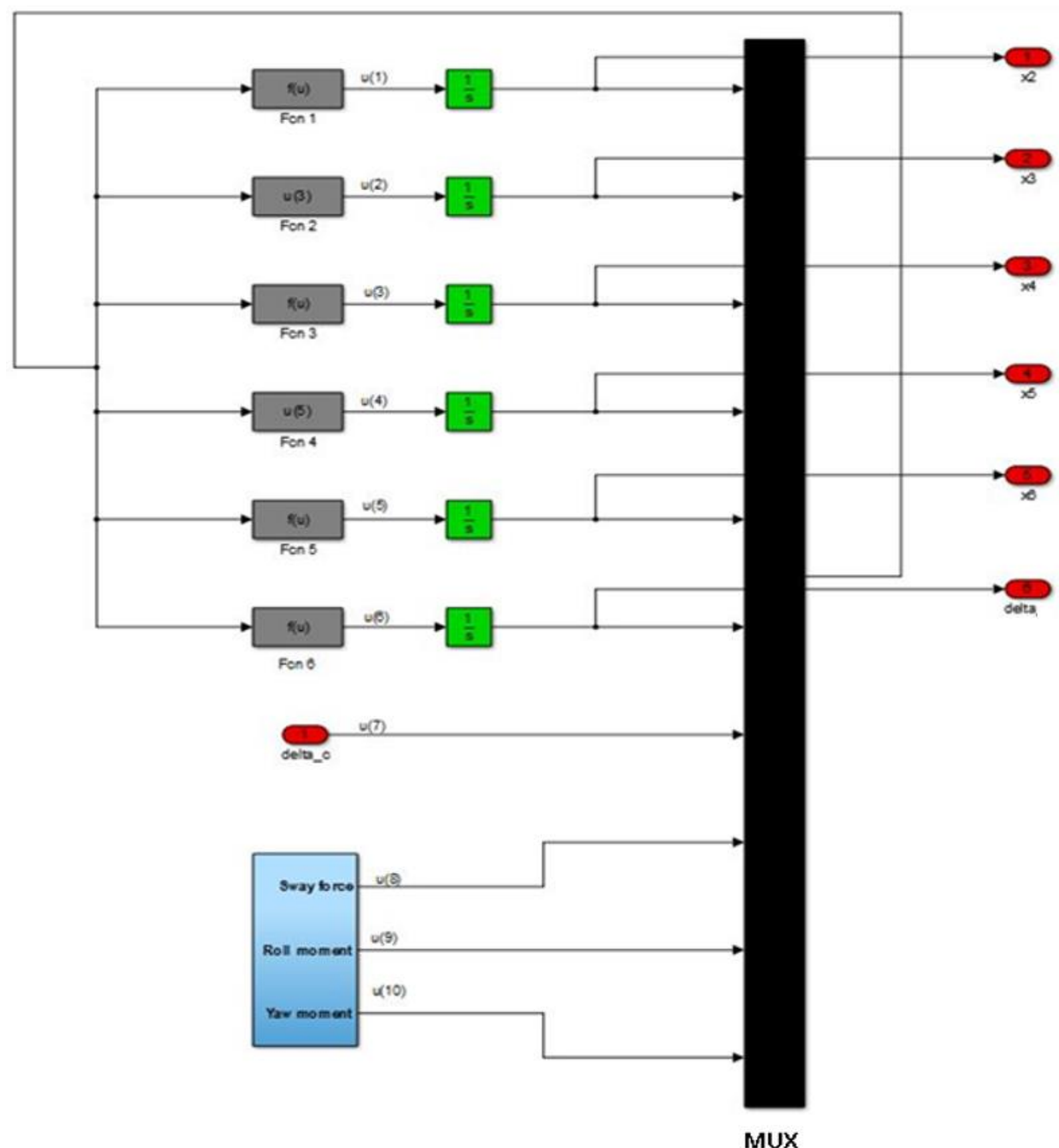

Fig.4: State space modelling of system matrix for Rudder Roll Stabilization

The optimal feedback gain is,

$\mathrm{K}=\mathrm{R}^{-1} \mathrm{G}^{\mathrm{T}} \mathrm{P}$

where $\mathrm{G}$ is the input matrix and $\mathrm{P}$ is unique positive semi-definite solution to the algebraic Ricatti equation. The optimal LOR feedback gain is

$\delta_{c}=0.1286 x_{2}+8.0879 x_{3}-22.5373 x_{4}+1.0000 x_{5}-12.6758 x_{6}-5.4954 \delta$

The mechanical limitations on the rudders with respect to amplitude and rate are also incorporated in the model for realistic simulations. The maximum rudder angle is limited to 35 degrees. Two rudder rates, $5 \mathrm{deg} / \mathrm{s}$ and 15 
$\mathrm{deg} / \mathrm{s}$ are used for simulation studies. The rudder amplitude and rudder rates are limited using a simplified mathematical model given by van Amerongen (1982) as shown in Fig. 5. The computational model is thus developed using MATAB and Simulink software and shown in Fig. 6. In the figure, the block named as system dynamics plus wave perturbation constitutes the state space modelling of the system presented previously in Fig. 4. For a full state feedback system, all states are used as the feedback for the controller design. The output from the limiter is then applied to the system dynamics to form a closed loop system.

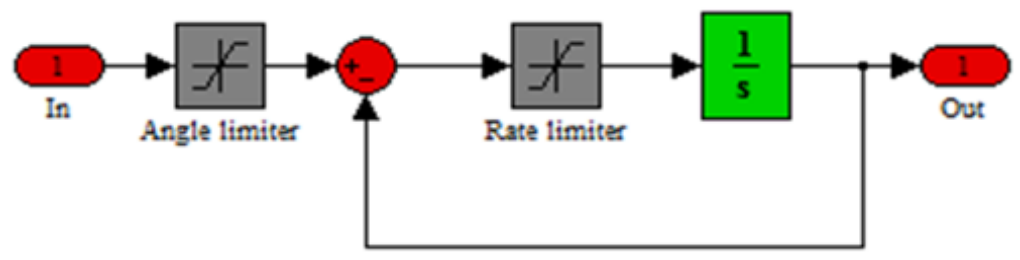

Fig. 5: Model for rudder angle and rate limits

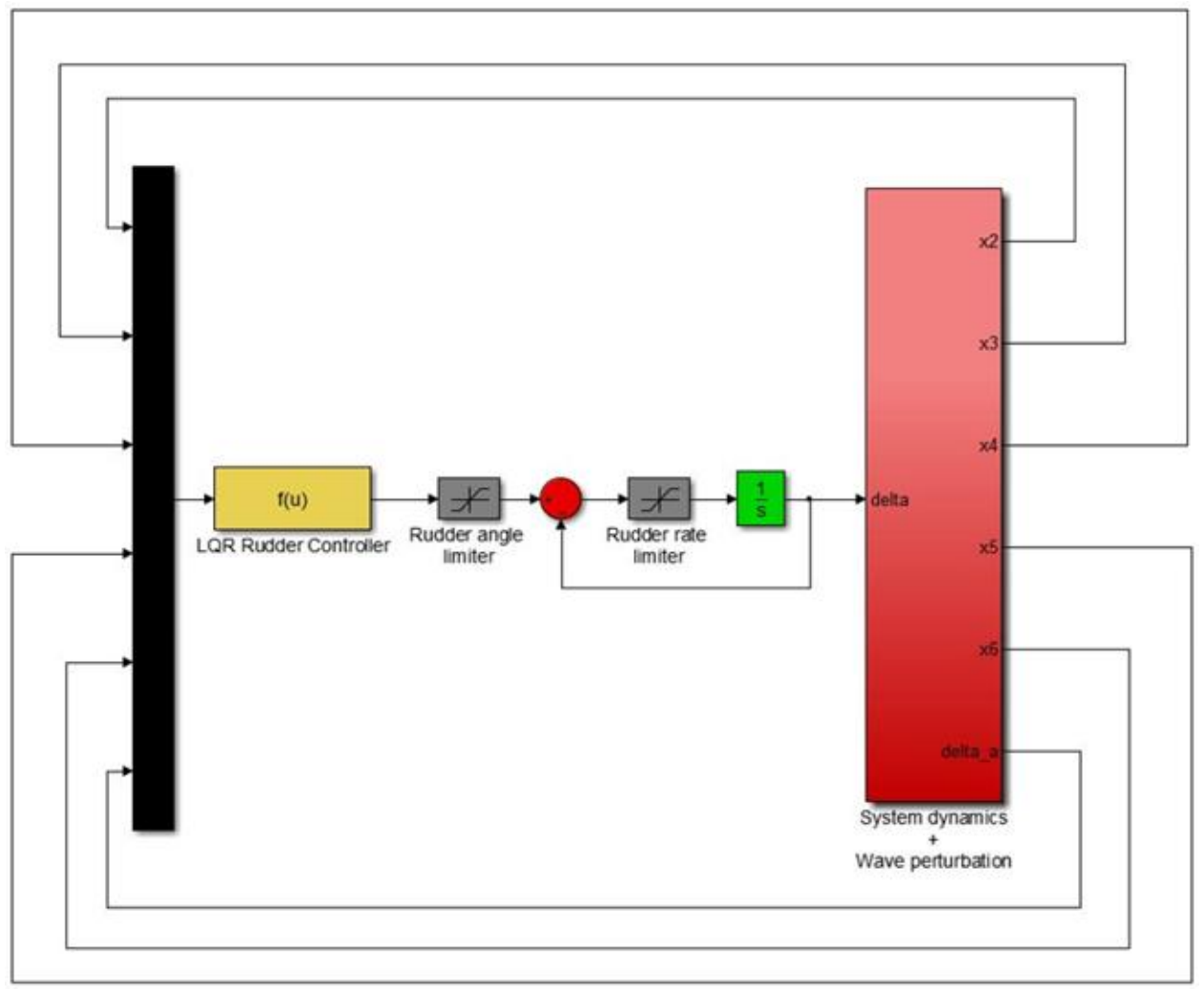

Fig. 6: Computational model for rudder roll stabilization system

\section{Results and Discussion}

The control objective of the RRS system is to deploy the rudder, which is primarily a path controlling device, to reduce the roll and without interference in the heading control. The simulations are carried out in two modes viz., (i) Autopilot - ON, RRCS - OFF, and (ii) Autopilot - ON, RRCS - ON mode. The first one records the roll motion without the control action and the second one records the reduced roll motion under active control by rudder movement. In both cases the autopilot is in active mode to correct deviations in the course heading. RRS is checked for its efficiency with respect to rudder rates and Sea State severity and discussed below. The values of the hydrodynamic coefficients for the candidate vessel are obtained using the seakeeping program SEAWAY.

\subsection{Effect of rudder rate on rudder roll stabilization}

It is implicit that the steering gear should have large fast turning capability. Higher rate of turn also implies that 
large capacity steering gear will have to be used for an efficient RRS system. This will ensure that there is effective roll reduction besides the yaw control by the rudder action. Faster rudder rates ensure that there is effective roll reduction besides the yaw control by the rudder action. Faster rudder rates increases the excursion angle of the rudder and produces the potential moment required for satisfactory roll reduction. The simulations are performed with two rudder rates, $5 \mathrm{deg} / \mathrm{s}$ and $15 \mathrm{deg} / \mathrm{s}$, for 3 different speeds and for Sea States of 4 and 5 . The sway-roll-yaw responses due to the influence of rudder rates for Sea State 4 and 5, with ship speed of 10 and 15 knots are shown in Figs. 7 and 8 respectively. An illustration of the controller output, the commanded rudder angle with 5 and $15 \mathrm{deg} / \mathrm{s}$ rudder rates are shown in Fig. 9. In both Sea State 4 and 5, with a relatively low rate of turn of the rudder at $5 \mathrm{deg} / \mathrm{s}$, there is appreciable variance in heading, though the autopilot maintains a zero mean heading. Slow rate of turn results in higher yaw angle deviations. This indicates the demerit of slow moving rudders for rudder roll stabilization. Similar trend is observed in the case of s way, the amplitude of rudder induced sway increases for a slow moving rudder. The roll reduction percentage obtained at this rudder rate is not significant. With relatively faster rudder rate of $15 \mathrm{deg} / \mathrm{s}$, the course deviation and rudder induced sway remains less. At this rudder rate, roll reduction is significant. A comparison in roll reduction percentage has been presented for both Sea States and rudder rate of turn. With faster rudder rate and increased forward speed, the effectiveness of rudder increases (See Figs.10 and 11). In case of heading, if the RRCS operates with low rudder rate of turn, as the vessel speed increases the deviation in heading also increases. This shows the significance of fast moving rudder to avoid the interference of RRCS with the steering control. Heading deviation comparison under autopilot control for Sea State 5 is presented Fig.12.
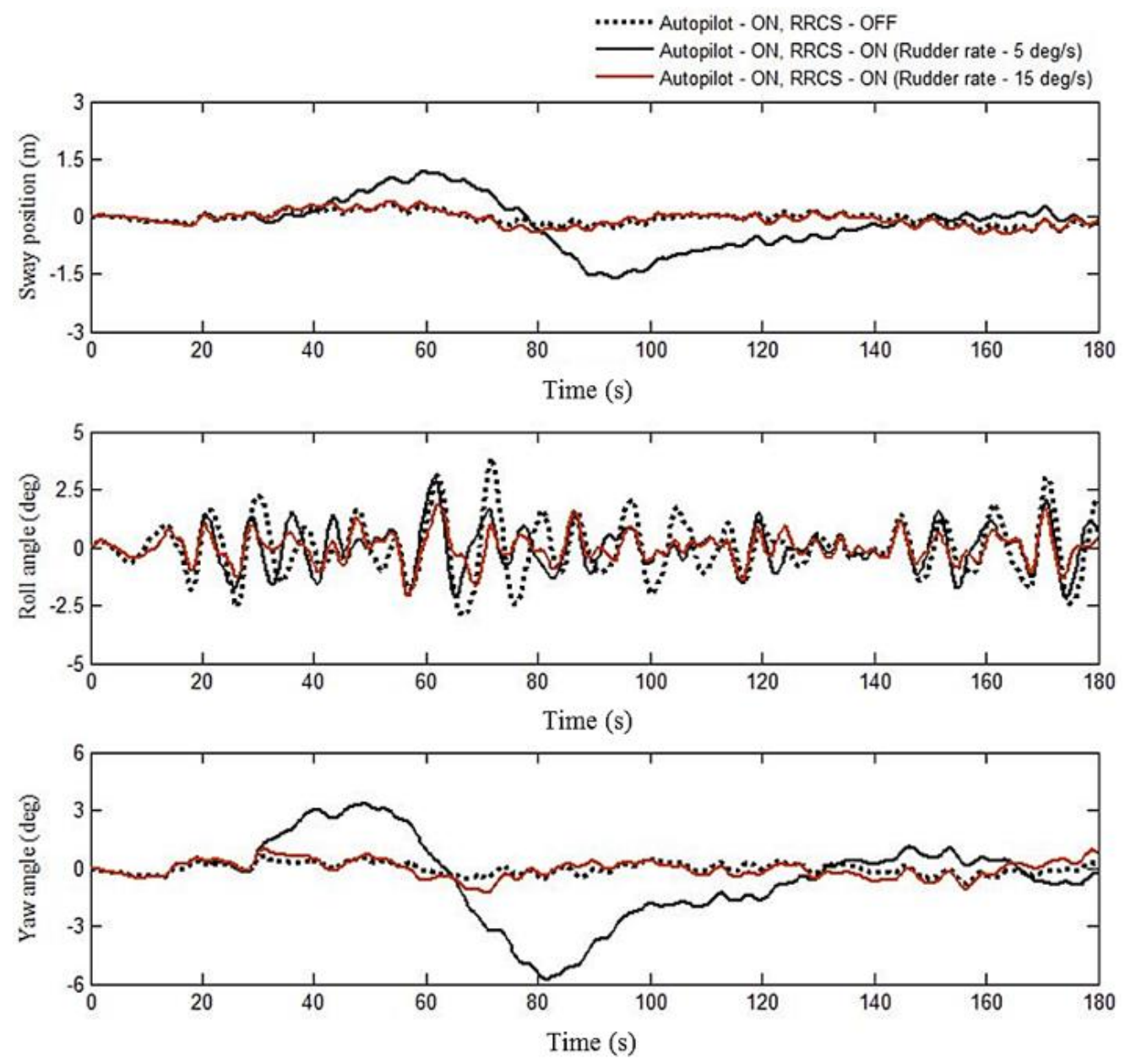

Fig. 7: Influence of rudder rate on sway-roll-yaw motions in Sea State 4, Ship speed 10 knots 

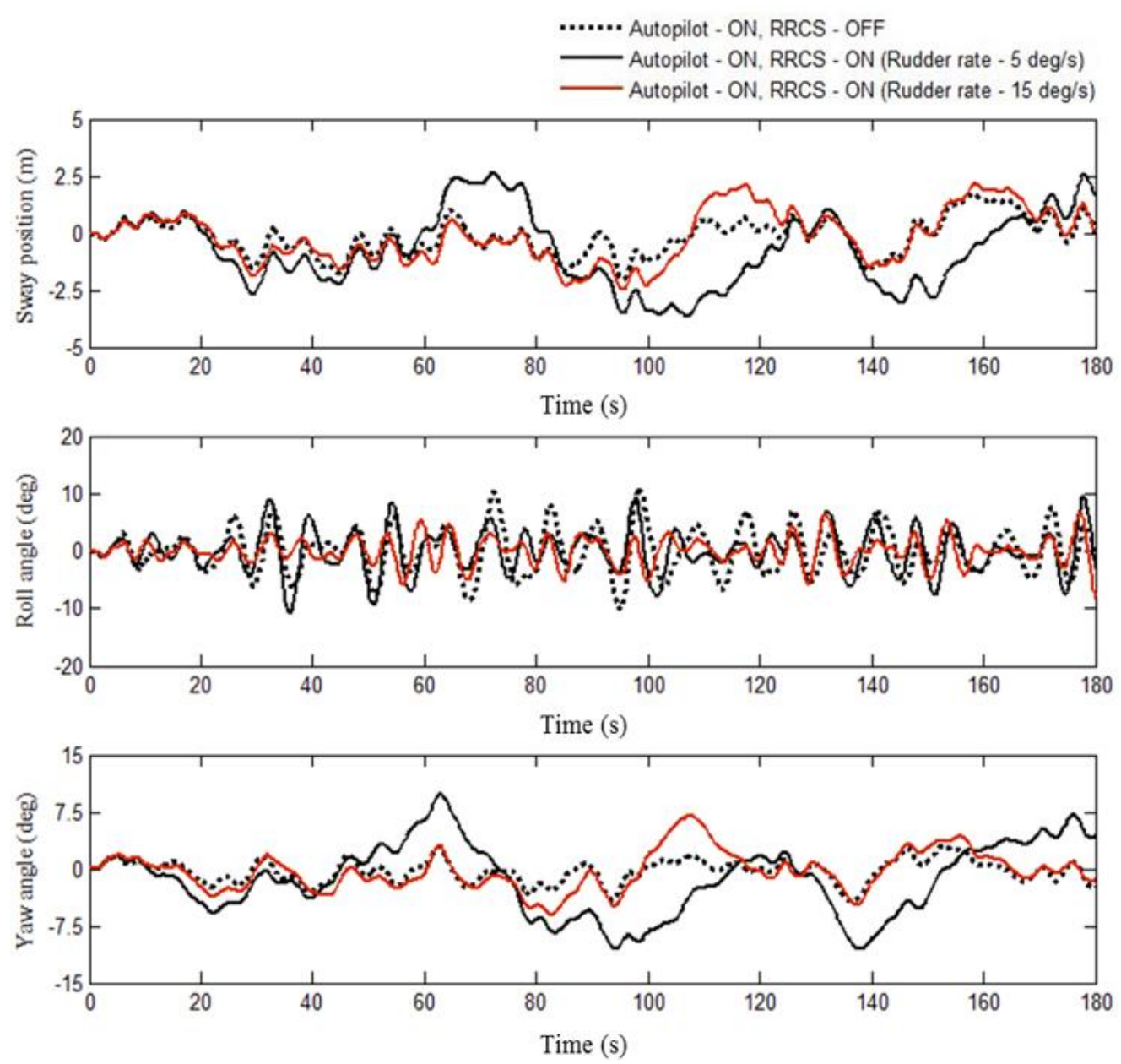

Fig.8: Influence of rudder rate on sway-roll-yaw motions in Sea State 5, Ship speed 15 knots
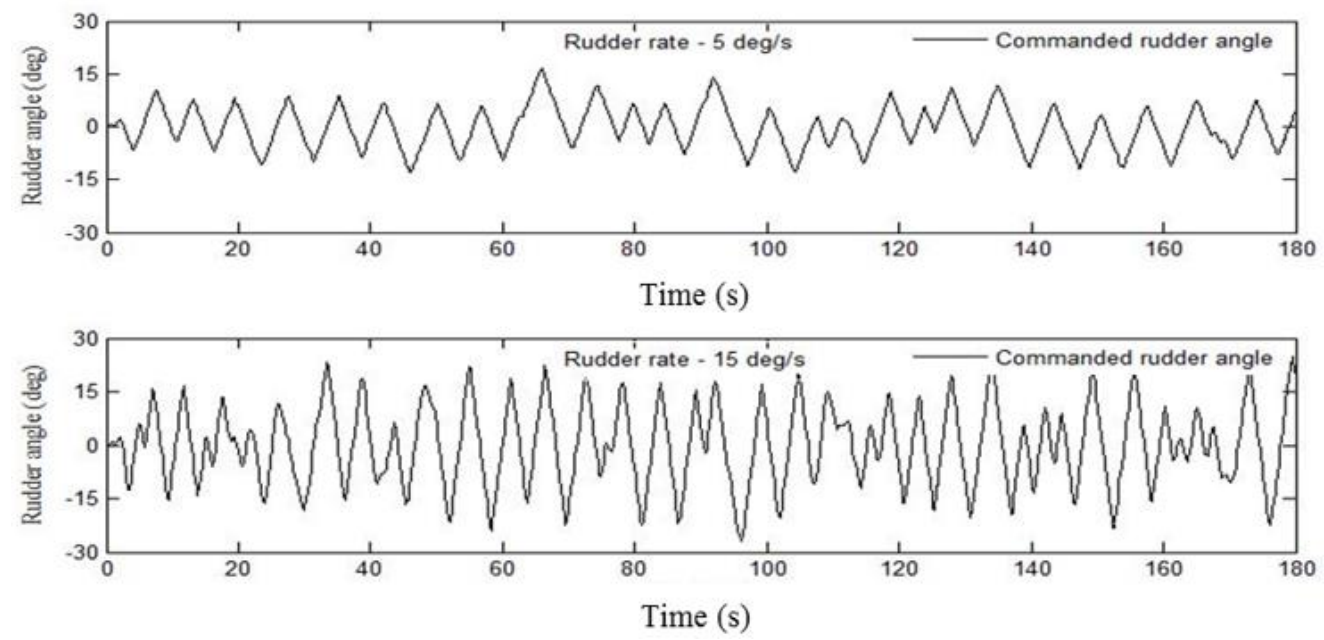

Fig. 9: Comparison of commanded rudder angle for RRS system with $5 \mathrm{deg} / \mathrm{s}$ and $15 \mathrm{deg} / \mathrm{s}$ rate of turn 


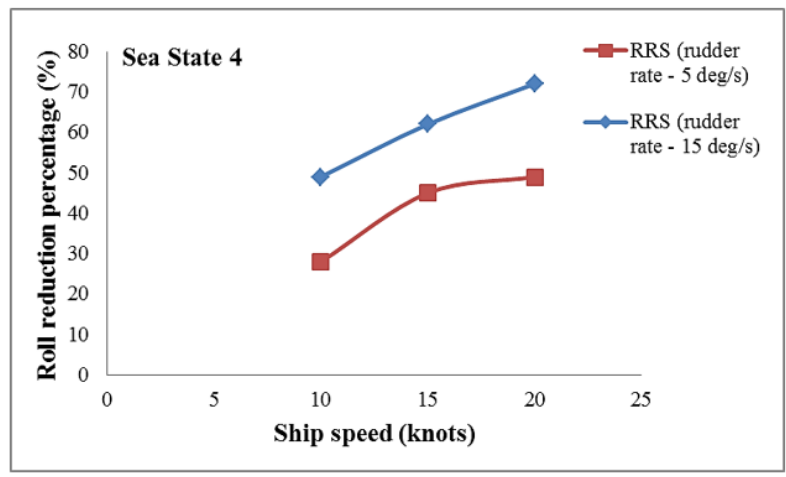

Fig. 10: Comparison of roll reduction due to different rudder rates for Sea State 4

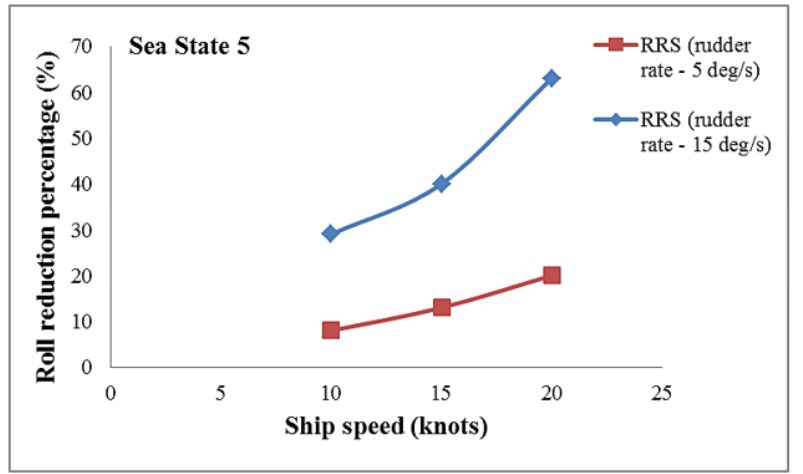

Fig. 11: Comparison of roll reduction due to different rudder rates for Sea State 5

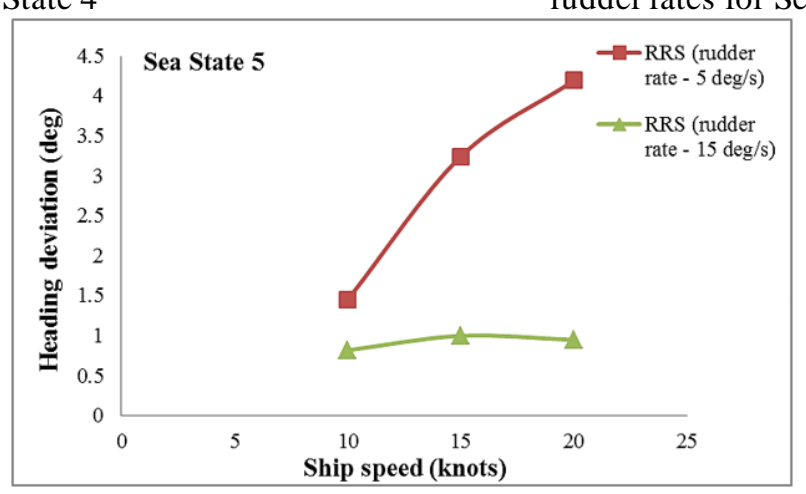

Fig. 12: Comparis on of heading deviation due to different rudder rates for Sea State 5

\subsection{RRS performance in Sea State 4 and 5}

The effect of sea severity on rudder roll stabilization performance is verified in Sea State 4 and 5 for ship speeds, 10, 15 and 20 knots with a rudder rate of turn $15 \mathrm{deg} / \mathrm{s}$. See Fig 13 to 16 for the results obtained for the speeds of 15 and 20 knots. Worsening Sea State causes drop of efficiency of roll reduction. Roll reduction is achieved maximum at Sea State 4. For all speed conditions, the percentage roll reduction drops when the ship is subjected from Sea State 4 to 5. At Sea State 4, 72\% of roll reduction is reported for the test speed of 20 knots. For the same speed, when the ship is subjected to Sea State 5, the percentage roll reduction drops by $9 \%$. It is seen that rudder based roll control is less effective at higher Sea State. However heading angle control is still effective when the rudder is operated with $15 \mathrm{deg} / \mathrm{s}$ rate of turn. An illustration of the controller output of rudder angle and the rate of turn of rudder for both Sea States at 15 knots ship speed is presented in Fig 17 and Fig 18. The figures confirm the capability of the control sys tem to adapt and prescribe the required rudder angle in the changing conditions.
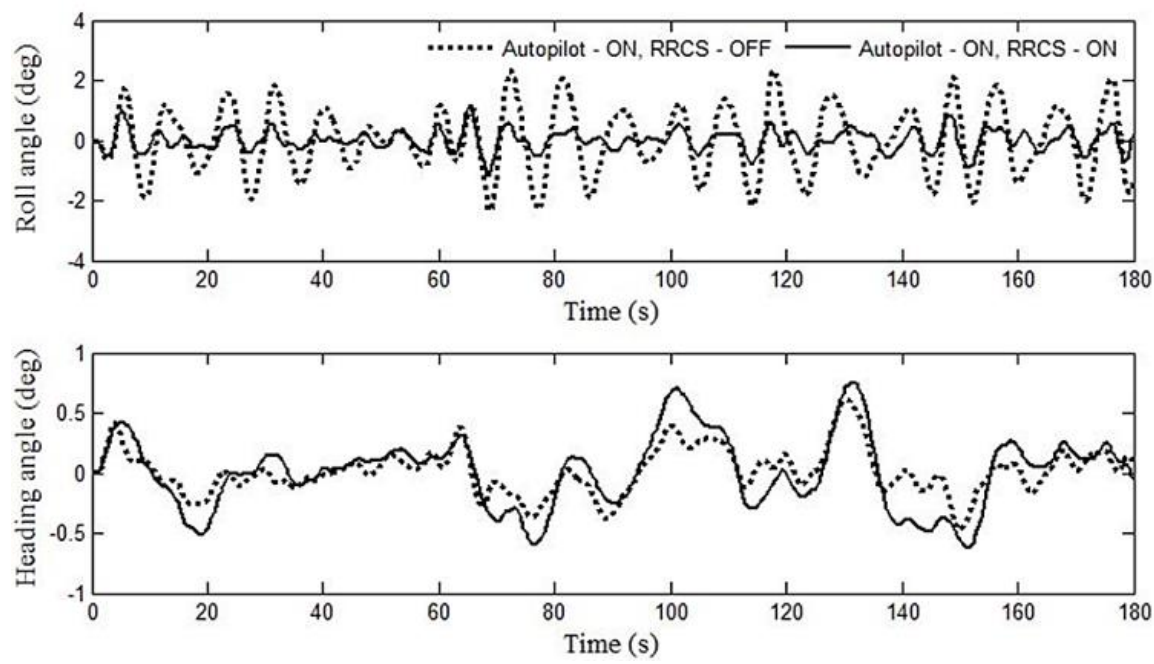

Fig. 13: RRS test results, Sea State 4 and ship speed 15 knots 

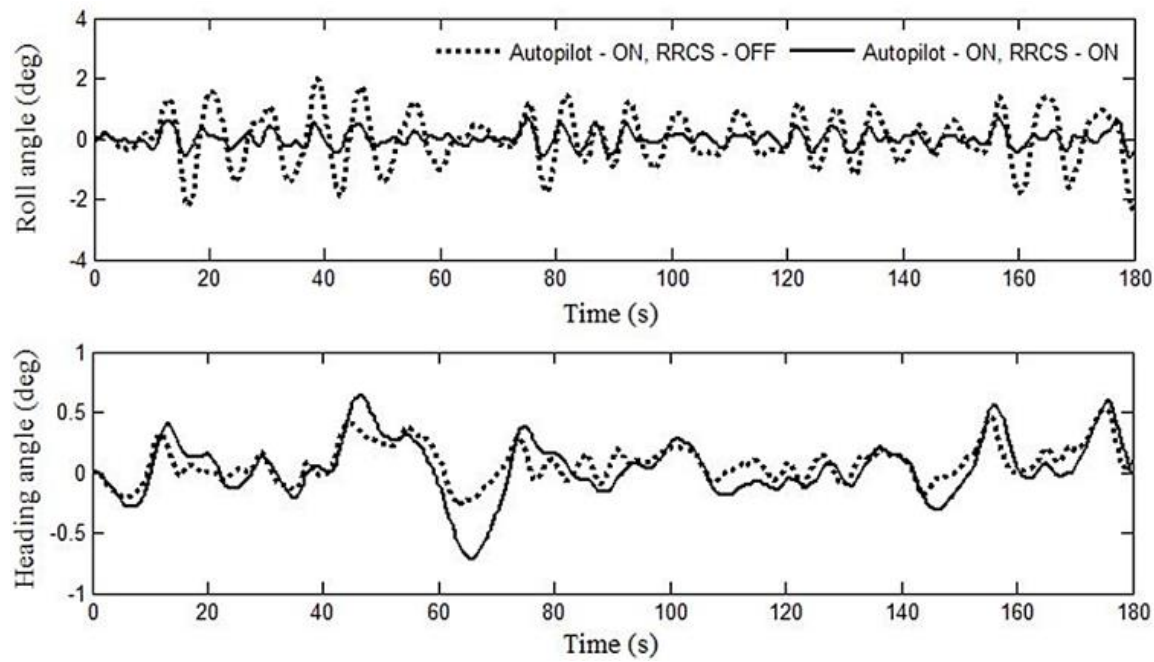

Fig. 14: RRS test results, Sea State 4 and ship speed 20 knots
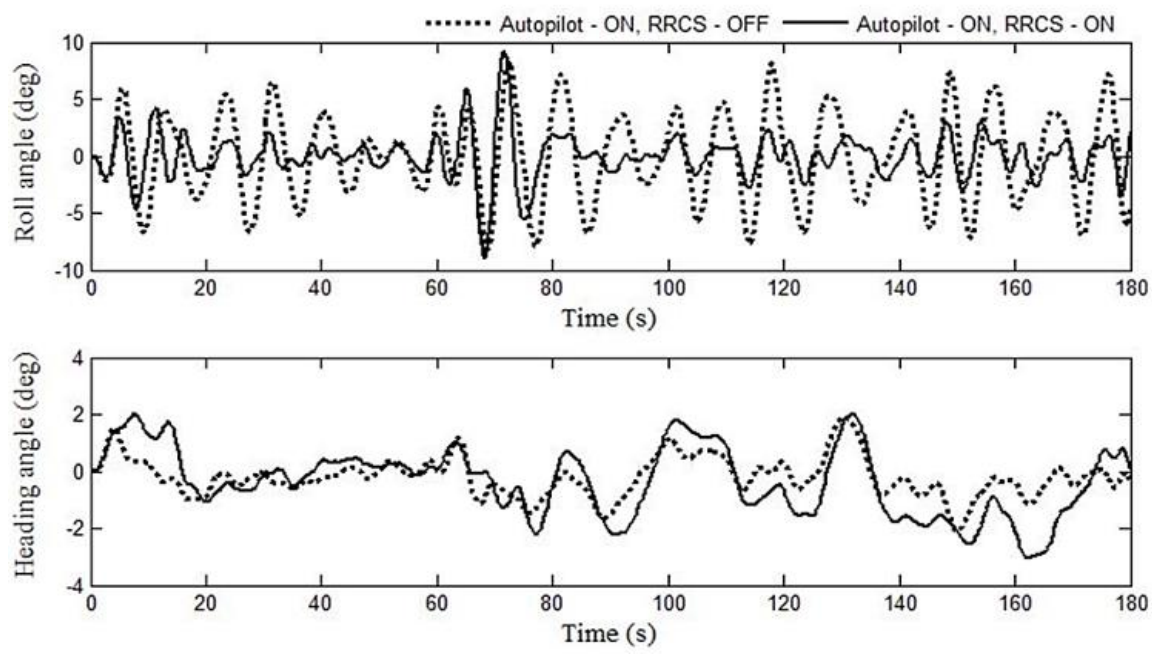

Fig. 15: RRS test results, Sea State 5 and ship speed 15 knots
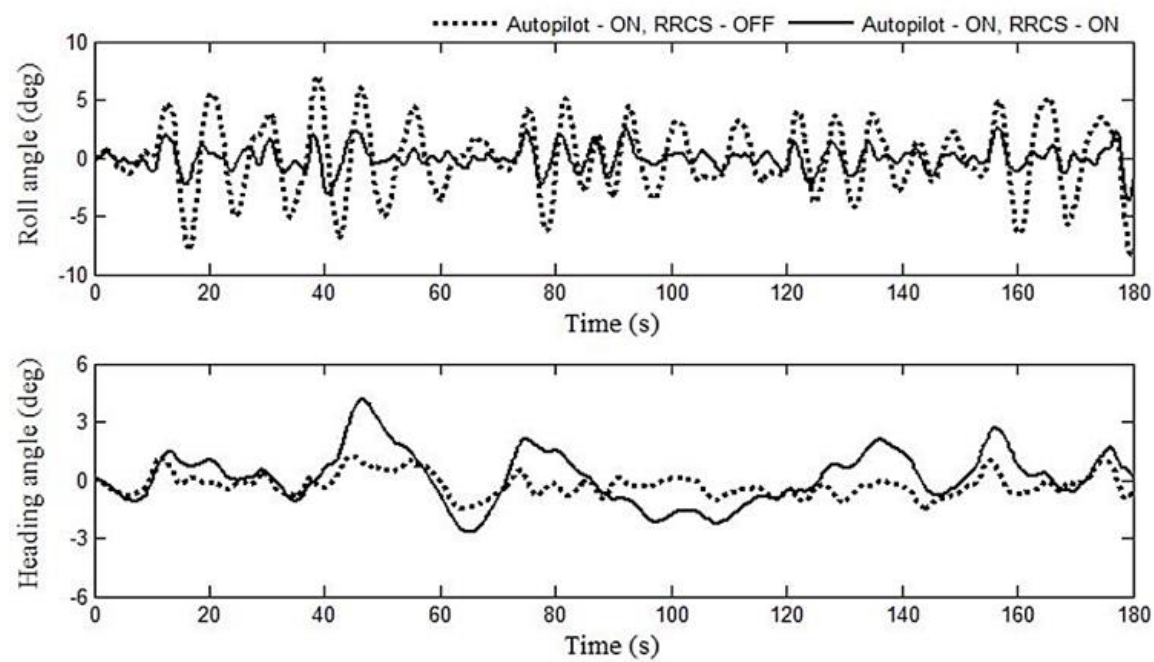

Fig. 16: RRS test results, Sea State 5 and ship speed 20 knots 

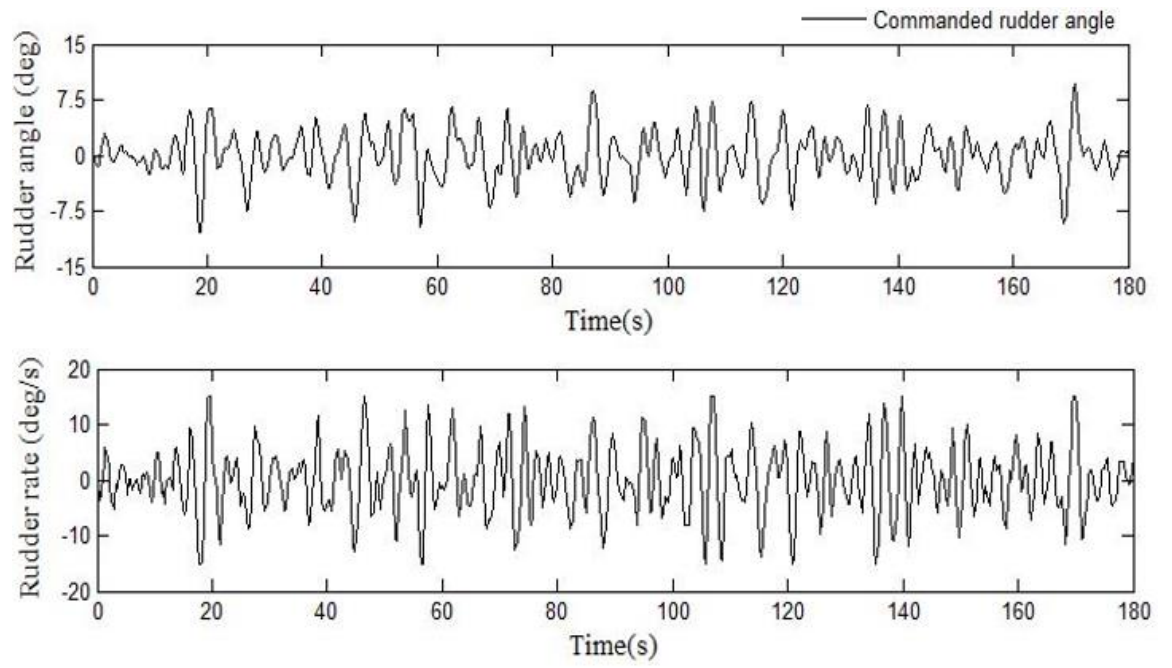

Fig. 17: Controller output for rudder angle and rudder rate for Sea State 4, Ship speed 15 knots
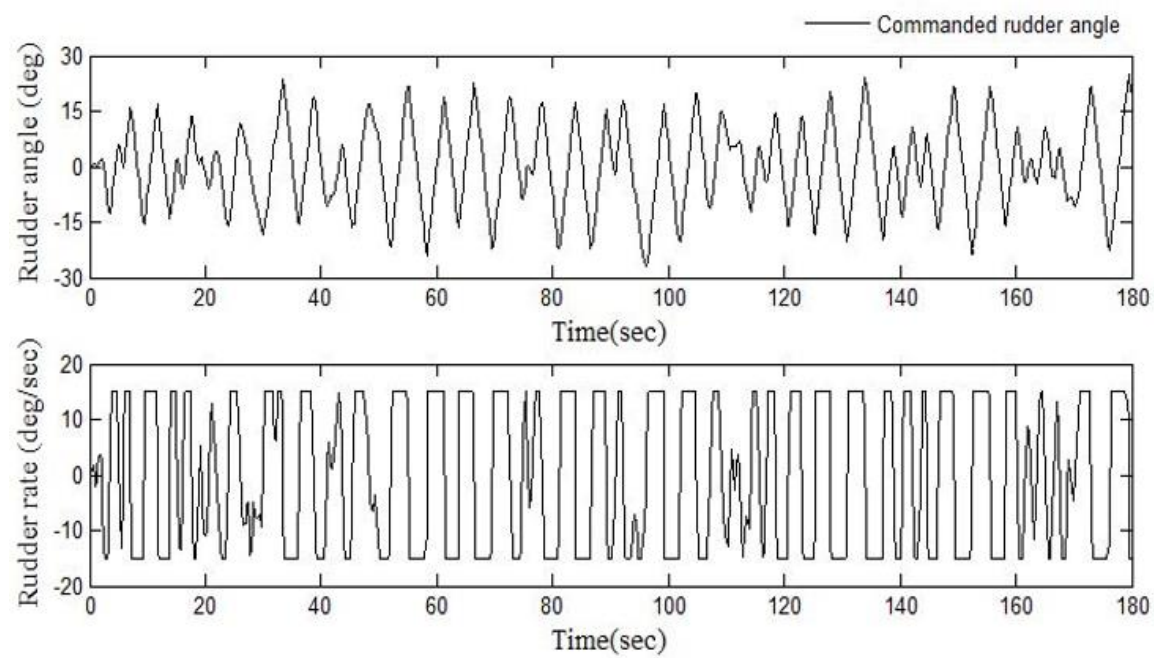

Fig. 18: Controller output for rudder angle and rudder rate for Sea State 5, Ship speed 15 knots

\section{Conclusion}

A closed loop 3-DOF state space model applicable for Rudder Roll Stabilization describing the sway-roll-yaw motion characteristics has been presented in this paper. The model has been developed in Simulink and exec uted through MATLAB. The performance of the system has been analyzed and reported using an optimal LQR controller. The wave perturbation to the system has been modelled using the method of shaping filter. The computational model has been demonstrated and checked for its efficacy. From the simulation results, at high rate of turn of rudder there is significant increase in the roll stabilization with good heading control. The sea state conditions also affect the roll reduction performance of the RRS system. The deviation in yaw angle is within the limits. A generalized model is presented here applicable for implementation to any ship to quantify rudder based roll motion stabilization. It is a general requirement that the rudder should be capable of higher rate of turn to achieve better roll reduction without adversely affecting the course of heading. The simulations show that the system is robust and stable.

\section{References}

Amerongen, V. J., Klugt, V. D. P. and Lemke, V. N. H. (1990): Rudder roll stabilization for ships, Automatica, 26, no. 2, pp. 679-690. https://doi.org/10.1016/0005-1098(90)90045-J

Baitis, M. E., Dennis, M. A., Woolaver and Beck, L. T. (1983): Rudder roll stabilization for coast guard cutters and frigates, Naval Engineers Journal. https://doi.org/10.1111/j.1559-3584.1983.tb01644.X

Blanke, M., Adrian, J., Larsen, K. and Bentsen, J. (2000): Rudder roll damping in coastal region sea conditions, 
Proceedings of the 5th IFAC Conference on Manoeuvering and Control of Marine Craft. https://doi.org/10.1016/S1474-6670(17)37048-9

Fossen, T. I. (2011): Handbook of Marine Craft Hydrodynamic and Motion Control, 1st ed., John Wiley \& Sons Ltd, United Kingdom. https://doi.org/10.1002/9781119994138

Hearns, G. and Blanke, M. (1998): Quantitative analysis and design of a rudder roll damping controller, IFAC CAMS, Japan

Journee, J. M. J. (2001): User Manual of SEAWAY, Delft University of Technology, Netherlands

Kallstrom, C. G. (1981): Control of yaw and roll by a rudder/fin stabilisation system, 6th Ship Control Systems Symposium, Vol. 2, Ottawa, Canada, 2.

Kallstrom, C. and Schultz, W. L. (1990): An integrated rudder control system for roll damping and course maintenance, Proceedings Ninth Ship Control Symposium,Vol. 3, pp. 278-296. Bethesda, Maryland: The Defense Technical Information Center, USA.

Kapitanyuk, Y. A., Proskurnikov, A. V. and Cao, M. (2016): Optimal controllers for rudder roll damping with an autopilot in the loop, 10th IFAC Conference on Control Applications in Marine Systems CAMS, Trondheim, Norway, pp 562-567

Majecki, P., Katebi, R. and Grimble, M. (2006): Rudder roll stabilization with nonlinear GMV control, International control conference (ICC 2006), Glasgow, U.K.

O'Brien, J. F. (2009): Multi-path nonlinear dynamic compensation for rudder roll stabilization, Control Engineering Practice, 17, pp. 1405-1414. https://doi.org/10.1016/j.conengprac.2009.06.008

Oda, H., Ohtsu, K. and Hotta, H. (1996): Statistical analysis and design of a rudder roll stabilization system, Control Engineering Practice, 4, no. 3, pp. 351 - 358. https://doi.org/10.1016/0967-0661(96)00012-3

Perez, T., Tzeng, C. Y. and Goodwin, G.C. (2000): Model predictive rudder roll stabilization control for ships, IFAC MCMC 2000, Denmark

Perez, T. (2005): Ship Motion Control - Course Keeping and Roll Stabilization Using Rudder and Fins, Springer-Verlag London Limited

Perez, T. and Blanke, M. (2012): Ship roll damping control, Annual Reviews in Control, 36(1), 129 - 147.

Roberts, G. N. (1993): A note on the applicability of rudder roll stabilization for ships, American Control Conference, San Francisco, CA, USA, 2403 - 2407

Sgobbo, J. N. and Parsons, M. G. (1999): Rudder/fin roll stabilization of the USCG WMEC 901 class vessel, Marine Technology, Vol.36, 157-170.

Shameem B.M., Subramanian V. A. (2014): Sea wave modelling for motion control applications, Journal of Naval Architecture and Marine Engineering, Vol.11, pp 29 - 38. https://doi.org/10.3329/jname.v11i1.17768

van Amerongen, J. (1982): Adaptive steering of ships - A model reference approach to improved maneuvring and economical course keeping, Delft University of Technology, The Netherlands.

Welch, P. D. (1967): The use of fast fourier transform for the estimation of power spectra: A method based on time averaging over short, modified periodograms, IEEE Transactions on Audio and Electroacoustics, Vol.15, 70-73. https://doi.org/10.1109/TAU.1967.1161901

Zhou, W. W., Chercas, D. B., Calisal, S. and Tiano, A. (1990): A new approach for adaptive rudder roll stabilization control, Ninth Ship Control Systems Symposium - SCSS, Bethesda, Maryland, USA, 15: 101-114. 